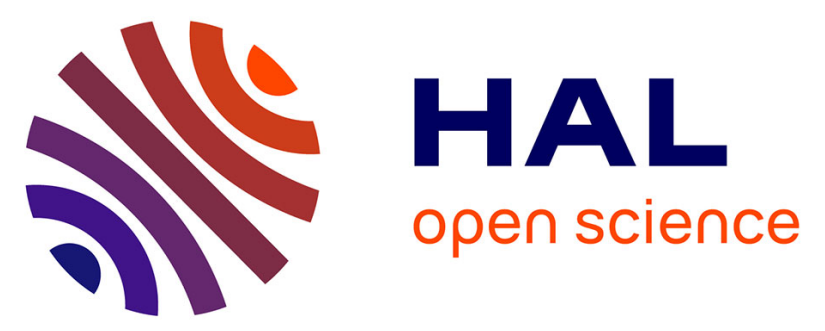

\title{
One-step synthesis and characterization of carbon nanospheres via natural gas condensate pyrolysis
}

Djamila Boufades, Souad Hammadou Née Mesdour, Anissa Moussiden, Hafsa Benmebrouka, Claire Hérold, Omar Kaddour

\section{- To cite this version:}

Djamila Boufades, Souad Hammadou Née Mesdour, Anissa Moussiden, Hafsa Benmebrouka, Claire Hérold, et al.. One-step synthesis and characterization of carbon nanospheres via natural gas condensate pyrolysis. Fullerenes, Nanotubes and Carbon Nanostructures, 2020, 28 (9), pp.716-723. 10.1080/1536383X.2020.1750383 . hal-03063877

\section{HAL Id: hal-03063877 https://hal.science/hal-03063877}

Submitted on 14 Dec 2020

HAL is a multi-disciplinary open access archive for the deposit and dissemination of scientific research documents, whether they are published or not. The documents may come from teaching and research institutions in France or abroad, or from public or private research centers.
L'archive ouverte pluridisciplinaire HAL, est destinée au dépôt et à la diffusion de documents scientifiques de niveau recherche, publiés ou non, émanant des établissements d'enseignement et de recherche français ou étrangers, des laboratoires publics ou privés. 


\section{One-step synthesis and characterization of carbon nanospheres via natural gas condensate pyrolysis}

Djamila Boufades ${ }^{a}$, Souad Hammadou ${ }^{a}$, Anissa Moussiden ${ }^{a, b}$, Hafsa Benmebrouka ${ }^{a}$, Claire Hérold ${ }^{c}$, and Omar Kaddour ${ }^{\mathrm{a}}$

${ }^{a}$ Petrochemical Synthesis Laboratory, FHC-UMBB, Boumerdès, Algeria; ${ }^{\mathrm{b}}$ Research Unit in Environmental Analysis and Technology, Development, Center for Scientific and Technical Research in Physical-Chemistry Analysis (UR-ADTE/CRAPC), Tipaza, Algeria; ' Institut Jean Lamour, Université de Lorraine, CNRS, IJL, Nancy, France

\section{ABSTRACT}

In the current work, carbon nanospheres (CNSs) were prepared via pyrolysis of gas condensate in $\mathrm{N}_{2}$ at $1273 \mathrm{~K}$ and atmospheric pressure for $2 \mathrm{~h}$ using ferric chloride as a catalyst precursor. X-ray diffraction, energy dispersive X-ray spectrometry (EDX) in scanning electron microscopy (SEM), transmission electron microscopy (TEM), Raman spectrometry (Raman), Fourier transform infrared spectroscopy, and thermal gravimetric analysis (TGA) are employed for the structural and morphological characterization of the nanomaterials formed. The conductivity of these films was measured using the four probe method. As results, SEM-EDX and TEM analysis reveal spherical shaped particles, with diameter varying between 100 and $200 \mathrm{~nm}$ and graphene interlayer distance of $0.339 \mathrm{~nm}$. The very low ID/IG ratio obtained reveals a relatively low amount of disorder in the nanostructures and TGA analysis implies that thermal stability was achieved after $470^{\circ} \mathrm{C}$. Our work provides a simple synthetic strategy in one-step sample preparation of CNSs, which can be used for furfur applications such as high-performance supercapacitors or adsorbents.

\section{Introduction}

Carbon, a sixth element in the periodic table, has ability to ond to itself. It is the most versatile element in terms of the variety of materials it may form. Inagaki [1] pointed out that the diversity of the texture in different scales was one of the characteristics of carbon materials. Carbon has many natural structures such as soot, an amorphous structure, diamond, a crystalline structure, graphite, and honeycomb lattice structure. With the technological advancement and understanding the properties of carbon, researchers are able to prepare verities of carbon containing materials from the micrometer to nanometer range. The shape and size of carbon nanomaterials can easily be tuned during the growth process to produce carbon nanoparticles in the shape of nanotubes, nanoflakes, nanoplates, nanorods, nanoballs, nanoonions, nanospheres, and many more.[2] Nevertheless, among all these allotropes, carbon nanospheres (CNSs) have been recognized as a new class of carbon structure with unique properties, such as light weight and high thermal resistance. In general, the sphere may indicate the simples form that a colloidal particle can easily adopt during the nucleation and growth process, as driven by minimization of interfacial energy. $[3,4]$ Spherically shaped carbon materials have been given many names, including carbon balls, carbon nanospheres, carbon microbeads, carbon blacks, onions, mesoporous microbeads, etc. [5] The spherical forms were classified according to their nanometric texture: concentric, radial, or random arrangement of the carbon layers.[1,4-7] Serp et al.[8] have classified these structures according to their size in three classes: carbon onions (2-20 nm, with a closed graphite layer), carbon nanospheres (50 nm-1 $\mu \mathrm{m}$ ) and carbon beads (above $1 \mu \mathrm{m}$ ). In the two past decades, CNSs have attracted significant attention in 
the fields of optoelectronics, medicine, engineering, chemistry, and physics, with highlights in lubricants, the development of nanodevices for better energy storage, combinatorial synthesis, encapsulating electrodes, separation technology, and others.[4,7-11] The success of all these applications strongly depends on the availability of spheres with tightly controlled sizes and surface properties. However, an economic method of preparing large amount of carbon spheres under reasonable experimental conditions is still lacking to date. In this regard, various elegant synthetic strategies have been successfully developed, such as chemical vapor deposition (CVD),[12-14] hydrothermal carbonization,[15,16] hard or soft templating method,[17] emulsion polymerization,[18] etc. Among the above-mentioned methods, the main process used for the synthesis of CNSs, both on a lab-scale and commercially, is the thermal chemical vapor deposition (CVD) as a promising technique, presenting a high selectivity, a moderate cost, low growth temperature (less than $1200{ }^{\circ} \mathrm{C}$ ), simple furnace, high efficiency, one-step process, control in synthesis parameters, and high purity of the product.[12-14] During the chemical vapor deposition, the carbon feedstock was decomposed at a specified temperature into carbon gas deposited on transition metal catalysts such as Fe, Co, or Ni. For example, Wang et al.[19] prepared CNS via the decomposition of benzene over an iron catalyst at $1000^{\circ} \mathrm{C}$ and Serp et al.[8] obtained a comparable spherical material after the decomposition of methane (in hydrogen) over an iron catalyst at $1100^{\circ} \mathrm{C}$. The ferrocene-catalyzed synthesis of CNS has also been reported in the literature using different carbon precursors at different temperatures by CVD process such as anthracene (900-1000 $\left.{ }^{\circ} \mathrm{C}\right)$ [20] or pentane $\left(900-1000{ }^{\circ} \mathrm{C}\right)$.[21] Unfortunately, conventional CVD methods suffer from various disadvantages, including employing high purity light hydrocarbons as carbon sources (such as methane, ethane, ethylene, etc.), resource intensive production processes, complex purification process, and energy consumption. This results in high price of the obtained CNSs. [22-24] Considering the high hydrogen and carbon content and high energy density, the production of CNSs from petroleum distillates provides a sustainable solution to both the upgrading of the distillate and the mass production of carbon nanomaterials. [24] For example, Alexandre and Luiz[25] fabricated CNSs by pyrolysis of three kind of petroleum residues using flow of nitrogen $(1.3 \mathrm{~L} / \mathrm{min})$ or argon (20 $\mathrm{mL} / \mathrm{min}$ ) at $800-1200^{\circ} \mathrm{C}$, without catalysts and in a continuous process. They concluded that the yielded nanospheres have similar properties, which were more influenced by the nature of the carrier gas and temperature. Moreover, carbon black and the soot obtained by the pyrolysis of commercially available kerosene, diesel oil, paraffin wax, and lubricant oil as precursors for the CNSs preparation were investigated by Mohan and Manjo.[26] The diameters of CNSs obtained were 62.48-108.41 nm, 48-57 nm, and 45-68 nm for kerosene, diesel, and lubricant oil, respectively.[26] Mohammed et al.[27] prepared CNSs from asphalt by CVD method under argon atmosphere $900{ }^{\circ} \mathrm{C}$ in quartz tube over $\mathrm{Co} / \mathrm{Al}_{2} \mathrm{O}_{3}$ catalyst material, obtaining carbon spheres with 30-240nm diameters. Carbon core shell nanospheres were fabricated by Ehab et al.[28] using bitumen-derived coal obtained from pyrolysis of petroleum bitumen at $600^{\circ} \mathrm{C}$ in argon atmosphere with average diameter of about 200-400nm in the product. Mohammad et al.[29] synthesized CNSs form the incomplete combustion of diesel with controlled air oxygen in special type of round bottom flax of glass, with size in the range of about $10-80 \mathrm{~nm}$ in diameter. In addition, Nandiyanto et al.[30] synthesized small CNSs from commercially available liquefied petroleum gas using a homemade burner that was connected with a flow of air $(600 \mathrm{~mL} / \mathrm{min})$. It could be clearly observed that catalyst, temperature, carrier gas and reactor design are the key parameters for converting raw material into reactive carbon clusters which would undergo the self-assembly process to generate carbon nanospheres. 
The aim of this work is to synthesize and characterize carbon nanospheres by natural gas condensate pyrolysis as a new precursors under $\mathrm{N}_{2}$ atmosphere. The highlight is an application of a simple one-step, low-cost method resulting in carbon spheres, involving the use of $\mathrm{FeCl}_{3}$ as a catalyst, nitrogen atmosphere and short times. The morphological, structural, thermal, and optical properties of as-synthesized nanoparticles were determinated using X-ray diffraction (XRD), energy dispersive Xray spectrometry (EDX) in scanning electron microscopy (SEM), transmission electron microscopy (TEM), Raman spectrometry (Raman), Fourier transform infrared spectroscopy (FTIR), and thermal gravimetric analysis (TGA).

\section{Experimental}

\subsection{Materials and samples preparation}

The chemicals and suppliers used in this study were as follows: anhydrous ferric chloride ( $\left.\mathrm{FeCl}_{3}, 6 \mathrm{H}_{2} \mathrm{O}, 99 \%\right)$, propanol $\left(\mathrm{C}_{3} \mathrm{H}_{8} \mathrm{O}, 98 \%\right)$, toluene $\left(\mathrm{C}_{7} \mathrm{H}_{8}, \%\right)$, nitric acid $\left(\mathrm{HNO}_{3}, 37 \%\right)$, and chloridric acid $(\mathrm{HCl}, 35 \%)$ were supplied by Sigma- Aldrich Company (all reagents used are chemically pure and were all used as received). Inert gas carrier (nitrogen gas, 99\%) was purchased from Rasgas-Algiers. Natural gas condensate sample as the carbon source was collected from Gassi-Touil Refinery in Algeria. Table 1 presents the gas condensate characteristics.

Table 1. Characteristics of Algerian gas natural condensate.

\begin{tabular}{|c|c|c|c|c|c|}
\hline Characteristic & $\begin{array}{c}\text { Density at } 15^{\circ} \mathrm{C} \\
(\text { ASTM D 1298) }\end{array}$ & $\begin{array}{c}\text { Refractive index, } \\
20^{\circ} \mathrm{C}\end{array}$ & $\begin{array}{c}\text { Molecular weight, } \\
\mathrm{g} / \mathrm{mol}\end{array}$ & Aniline point, ${ }^{\circ} \mathrm{C}$ & $\begin{array}{c}\mathrm{TVR}^{2} \text { ASTM D 1267 } \\
\text { Psi }\end{array}$ \\
\hline Value & 0.7170 & 1.4112 & 117.8 & 64 & 7.20 \\
\hline
\end{tabular}

Carbon nanospheres were produced via direct pyrolysis of gas condensate in an inert atmosphere (nitrogen) via CVD method. First, $0.07 \mathrm{~g}$ of $\mathrm{FeCl}_{3}$ powder was dissolved in $10 \mathrm{~mL}$ of propanol solution and then the mixture was stirred for about $5 \mathrm{~min}$. After that, $30 \mathrm{~mL}$ of natural condensate gas was added and mixed with $10 \mathrm{~mL}$ of the above mentioned catalytic solution. The CNSs synthesis was carried out in a CVD reactor as illustrated in Figure 1. The CVD configuration is composed horizontal quartz tube $(0.027 \mathrm{~m}$ diameter and $0.9 \mathrm{~m}$ length) loaded in a tubular furnace using fresh feed stock (gas condensate and catalyst solution). The furnace was heated to the growth temperature at $1000^{\circ} \mathrm{C}$. At this temperature, $0.34 \mathrm{~mL} / \mathrm{min}$ of mixture was blown into the furnace for $2 \mathrm{~h}$ for CNCs to be grown up in the presence of nitrogen (99.99\%) as a carrier gas at a rate of 100 $\mathrm{mL} / \mathrm{min}$. The flow of both the feed stock (gas condensate) and N2 was optimized until the desired size had been attained by MODDE 6, accordingly to our previous work.[31] The furnace was then cooled down to room temperature under the nitrogen flow. The product containing CNCS was collected from the vessel. After calculating theoretical carbon deposition and weighing experimental carbon deposition, the $\mathrm{CNSs}$ purification process by $\mathrm{HCl}$ and $\mathrm{HNO}_{3}$ acid solutions are carried out. The oxidation method used in this $100 \mathrm{~mL}$ of mixture of nitric acid (65\%) hydrochloric acid (35\%) solutions. The mixture refluxed for $2 \mathrm{~h}$ at $115^{\circ} \mathrm{C}$. The oxidized CNS was filtered, then washed with doubledistilled water and dried under vacuum at $100^{\circ} \mathrm{C}$ for $10 \mathrm{~h}$. 


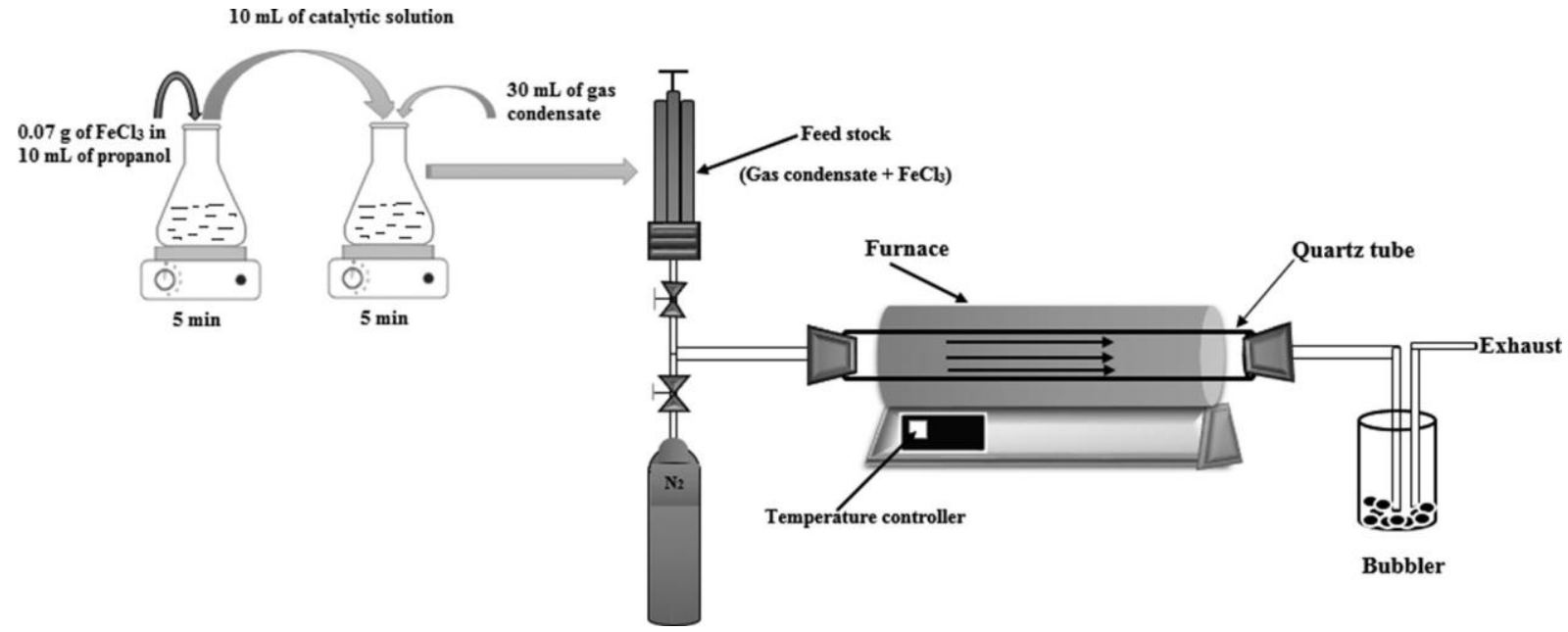

Figure 1. Main steps for the experimental CNSs synthesis via natural gas condensate pyrolysis.

\subsection{Characterization}

The size, surface, and the morphology of the CNSs particles are characterized by energy dispersive X-ray spectrometry (EDX) in SEM (FEI QUANTA 600 W), Transmission electron microscopy (TEM, Jeol CM 200). Standard automated powder diffractometer (XRD, PANalytical: EMPYREAN) was used with Cuo-radiation with $514 \mathrm{~nm}$ laser excitation, and Raman spectroscopy (Raman, Horiba HR 800 UV) were employed to observe the structure of as-prepared CNSs. FTIR (Perkin Elmer Spectrum 100 instrument) was employed for chemical analysis, and the thermal stability was investigated by TGA (Setsys Ev 1750 TGA-SETARAM). The electrical properties of the thin as-prepared CNSs films coated on alumina substrates were explored by the four-point probe method using a source meter (JANDEL RM3000) and "fluke" electrodes.

\section{Results and discussion}

Gas condensate has been used as a carbon precursor to synthesis CNSs via pyrolysis, to our knowledge, which has never been reported in the literature. After being heated, gas condensate would decompose, resulting in a large amount of small molecules and carbonaceous species. Figure 2 shows

samples obtained from the quartz tube wall surface, fine powder, and mirror-like lamella with mirror and dark sides. All samples obtained were characterized by both a mirror side and a dark side. The results obtained here are similar to those observed by others researchers, and they suggest that the mechanism of formation of carbon is influenced by both the environmental and the nature of solid surface on which carbon is nucleated.[6,32] Figure 3 shows SEM-EDX of as-prepared CNSs. These particles seem to form a network-like structure by joining together. As can be seen, all samples (fine powder and dark side lamella) show the same morphology (Figure 3c-e), while the mirror-like lamella side shows more disordered graphitic layers (see Figure $3 \mathrm{~b}$ ). The CNSs obtained in this research are similar to those synthesized by other researchers using different precursors that allows the formation of the smallest spheres (100-200 $\mathrm{nm})$ according to experimental conditions. $[6,27,28,33]$ It can be seen that the formed nanoparticles have a non-uniform, discrete spherical shape particles with curved surface and an average diameter from 100 to $200 \mathrm{~nm}$. As can 
be observed the CNSs are presented as a conglomeration of spherical bodies. This may be attributed to extended reaction times and as the cooling process from synthesis to room temperature.[34] Nieto-Marquez et al.[35] suggested that the coalescence of spheres must be attributed to the presence of reactive dangling bonds on their surface, providing them with a high surface reactivity; or it is related to the temperature increasing; it means that the susceptibility of the CNSs is high, as consequence, they make conglomerates quickly on the surface; this effect has been reported by other researchers.[6,14,36] As reported by Tiwari et al.[18] the commonly presence of various carbon nanospheres, such packing/aggregation is highly desirable, and generates the valuable hierarchical macro-/meso-/micropore structures in the carbon materials which facilitate their applications as superior high-rate electrode materials and fast-adsorbing sorbents. The cross sectional images (Figure 3c) of the broken particles reveal that the formed CNSs are not hollow and are made of several graphitic layers which are concentrically arranged around their core; which mean with concentric carbon layers of growth-type. Some CNSs particles are comprised of a single core surrounded by several concentric disordered graphitic layers and has a resemblance to an actual onion; while others CNSs particles were observed to have more than one core which are jointed together and share several common outer graphitic layers.

The analysis of energy dispersive spectroscopy indicated elemental

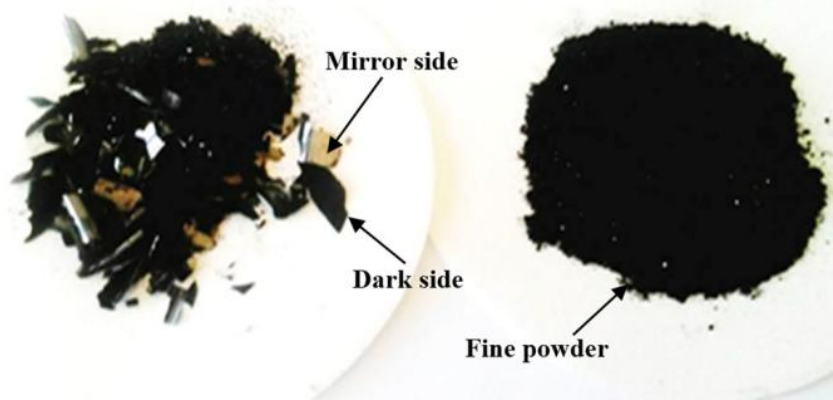
composition of CNSs presented in Figure 3f. Scanning points reveal that all spheres have above $99 \%$ carbon content and a small quantity of oxygen. The CNS has not required any additional purification method.
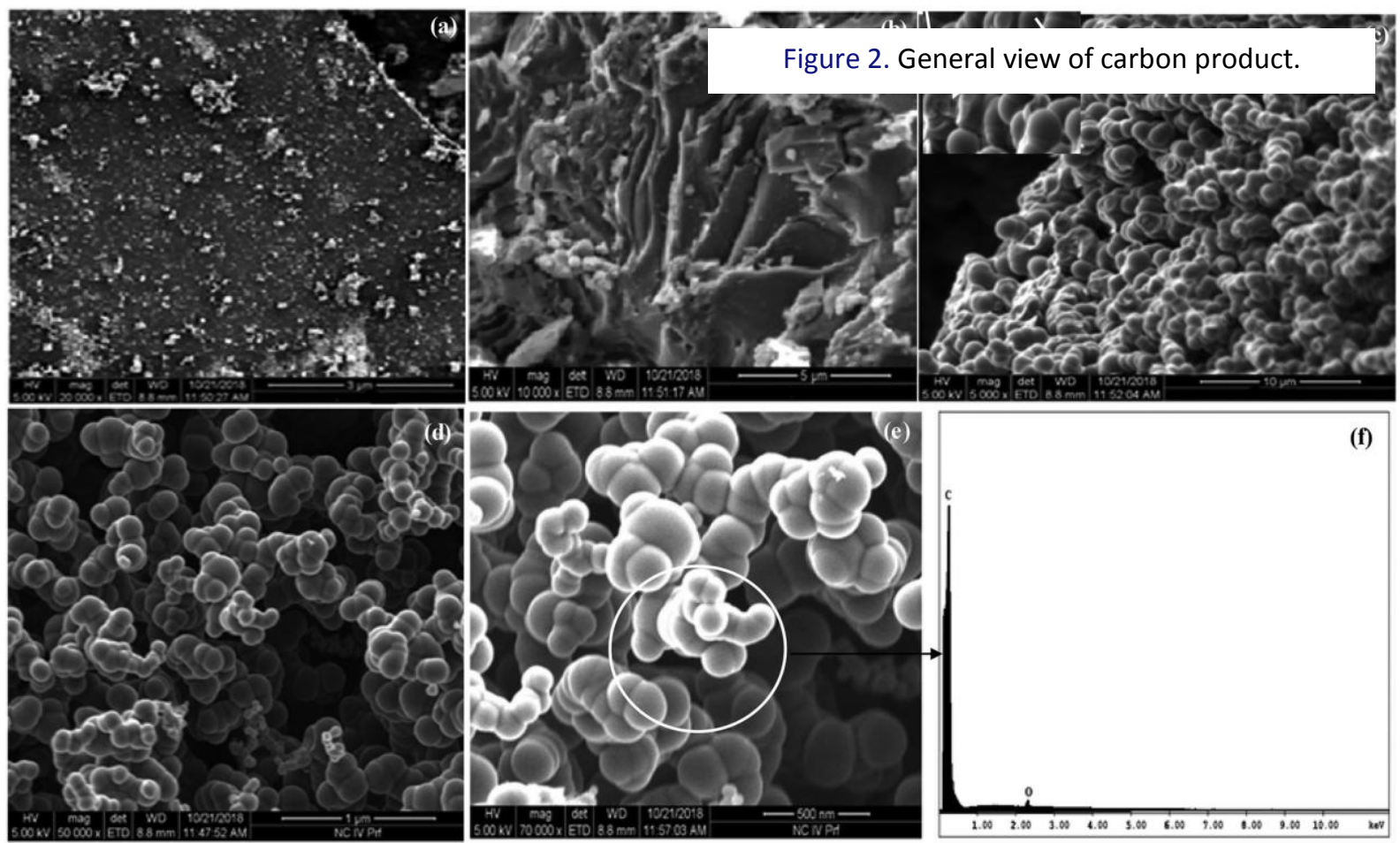

Figure 3. SEM images of the CNSs generated in CVD wall quartz tube. The cross section views $(a, b)$ of mirrorlike side of lamella at different magnification, (c) the cross section images of the broken CNSs obtained from 
dark side of lamella showing concentric graphitic layers arranged around a single core and multiple cores (pointed by arrows), the carbon spheres have a wide range of sizes: (d) bigger and (b) smaller particles obtained from fine powder, and (f) EDX spectrum taken from the marked area.

As presented in Figure 4, the nanostructure of CNSs sample is composed by a large number of carbon nanospheres on the surface with broad size/shape distribution and the crystalline structure of the CNSs particles was more clearly visible under TEM. Almost all of the particles were found to be assembled in a chain-like branched structure (Figure $4 a, b)$. The average interlayer separation between the graphitic sheets as obtained from the magnified TEM images was $0.339 \mathrm{~nm}$. The diffraction pattern (lower inset of Figure 4b) of an NCSs particle shows a bright ring pattern corresponding to the different planes of graphite. The diffraction pattern indicated the turbostratic nature of the graphitic planes in the NSCs particle. The TEM and SEM images solidly confirm the successful synthesis of CNSs with small sizes in the desired range of 100-200 nm by this proposed process. The XRD pattern of the CNSs product is depicted in Figure $5 \mathrm{a}$ and shows two diffraction peaks situated at $2 \theta=26.26^{\circ}$ and $44.48^{\circ}$ corresponding to the (002) and (100), respectively according to JCPDS 00-065-6212 card. These peaks were reported by other researchers for CNSs synthesis.[37] According to the Scherrer formula, the graphitic line C (002) correspond to interlayer spacing of about $0.339 \mathrm{~nm}$, if a slight decrease in the d002 suggests a better packing of the graphene layers.[38] There are no peaks of other materials in this XRD pattern, probably suggesting the high purity of the product. The Raman spectra in Figure 5b show two prominent peaks located near 1342 and $1588 \mathrm{~cm}^{-1}$, commonly denoted as D- and G-bands respectively. The D-band is caused by the presence of disruptions in sp2 bonding like dangling bonds, heptagon and pentagon carbon rings, foreign atoms, vacancies and amorphous carbon. Herein, the intense D band in the Raman spectrum of CNSs is caused mainly by heptagon and pentagon rings, which are essential to produce curved shapes in carbon spheres.[4,6,7,13,39,40] The $G$ band in the Raman spectrum is caused by sp2 hybridized carbon atoms. The ID/IG value of synthesized CNSs was estimated to be 0.81 . This is lower than the values reported for CNSs particles synthesized by other researchers [6,39] and it reflects a relatively better degree of graphitization. Preferably, for nanocrystalline carbon, this value is sought to be as low as possible.[41]
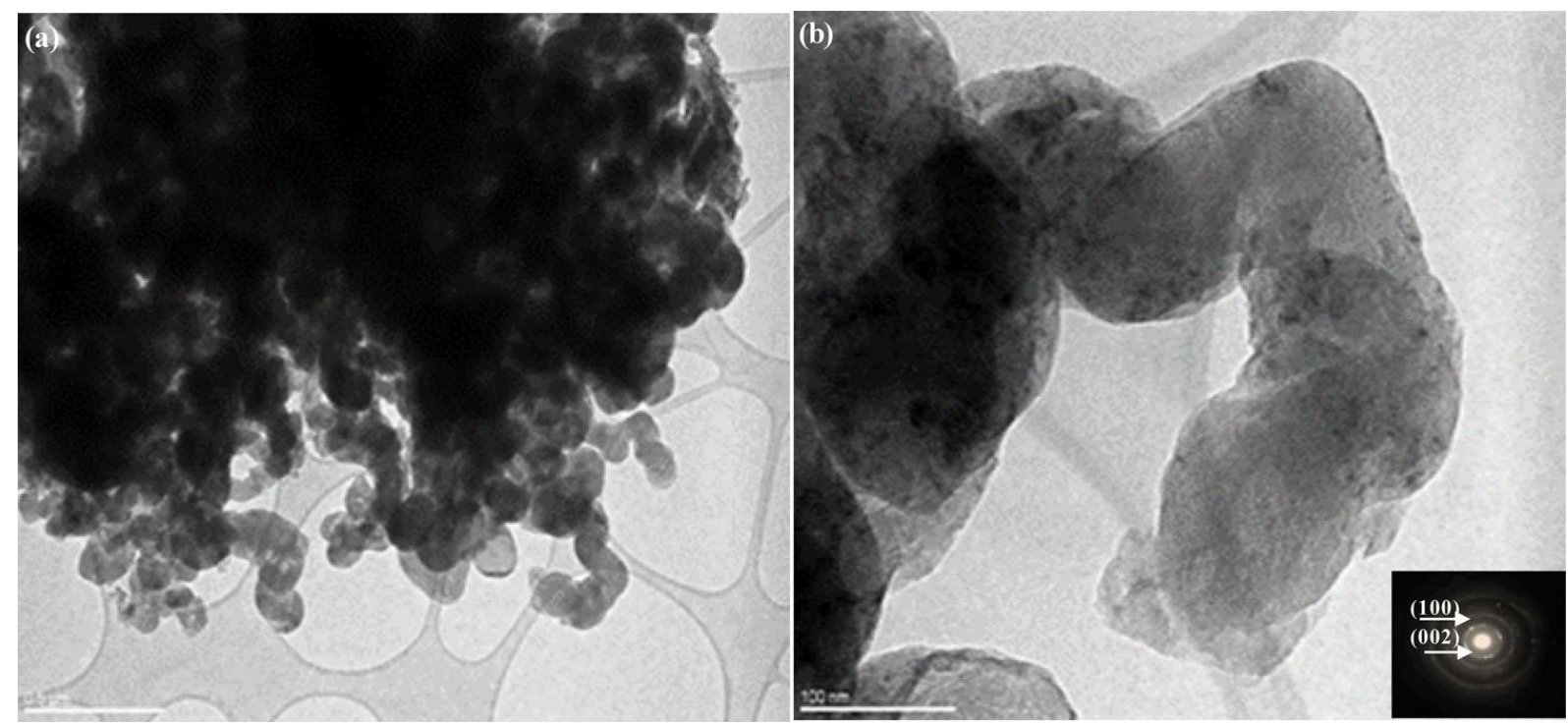
Figure 4. TEM images depict the spherical CNSs formed in wall surface of quartz tube and the lower inset in Figure $4 \mathrm{~b}$ is the electron diffraction pattern of an individual CNS particle.
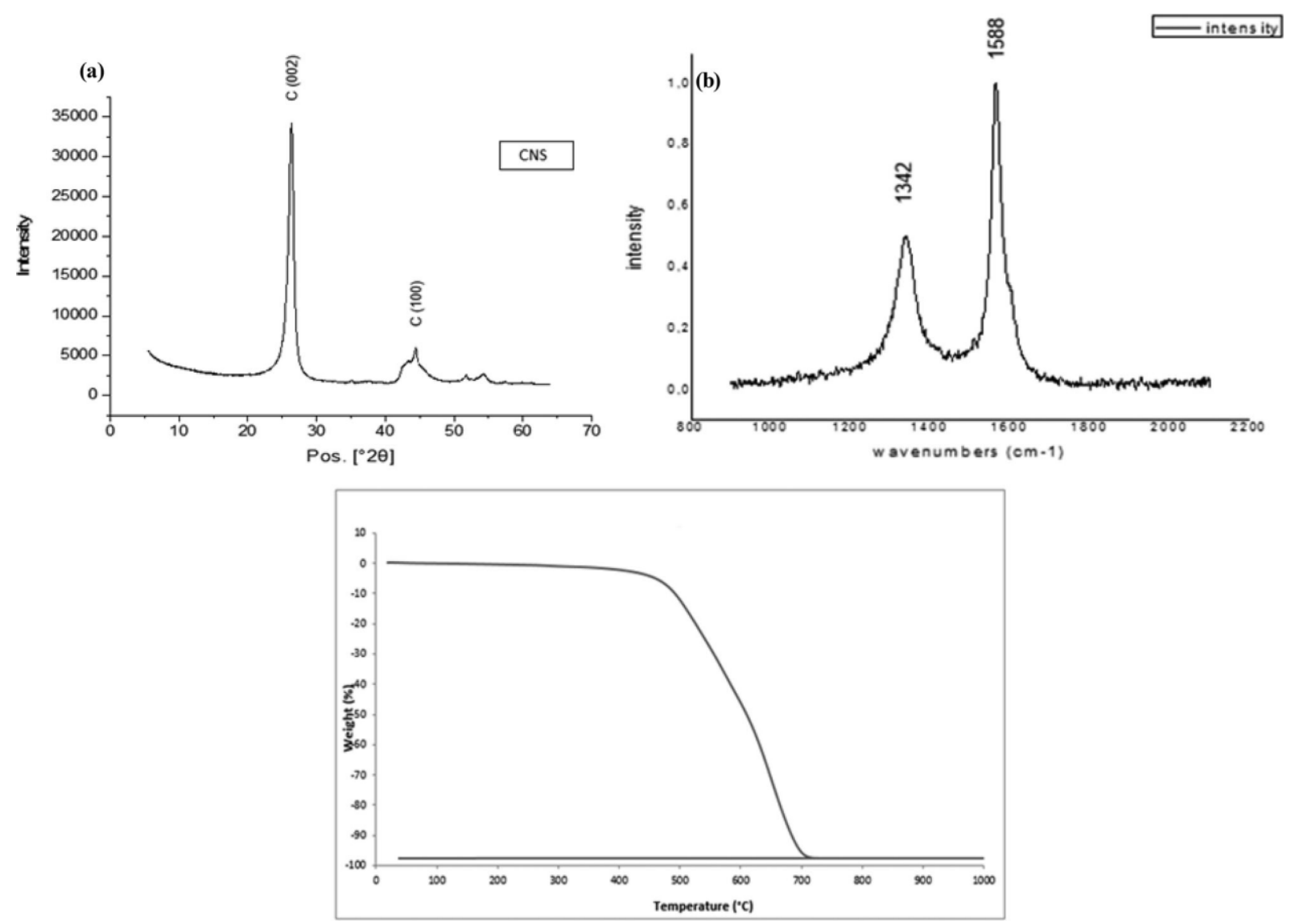

Figure 5. (a) XRD pattern Raman spectra, (b) Typical Raman spectra, and (c) representative of TGA curve of the as-synthesized CNSs.

The TGA curve of the as-prepared CNSs particles shown in Figure $5 c$ and compare its thermal stability by examining its decomposition behavior in the presence of air. The analysis was executed under air heating from $40{ }^{\circ} \mathrm{C}$ to $1000{ }^{\circ} \mathrm{C}$ at $10{ }^{\circ} \mathrm{C} / \mathrm{min}$. The weight loss started at $470{ }^{\circ} \mathrm{C}$ and ended at around $730 \mathrm{C}$. A minor weight loss is found just below $300^{\circ} \mathrm{C}$ may be due to evaporation water contents or volatile substances such as hydroxyl groups, $[42,43]$ just below $470{ }^{\circ} \mathrm{C}$, a rapid weight loss of CNSs is observed in the temperature range of $470-730^{\circ} \mathrm{C}$, which indicates that there are a large number of lattice defects in the structure of the CNS that allow oxygen to easily enter the spheres and facilitate a rapid oxidation of the sample.[43] The oxidation process continued until all the carbon soot was completely oxidized. Furthermore, TGA analysis reveals that the CNS purity is about $97.66 \%$, confirmed by the EDX spectrum shown in Figure $3 f$.

Figure 6 shows the FTIR spectrum of the CNSs sample. The band at $3432 \mathrm{~cm}-1$ correspond to the elongation vibration of free $\mathrm{OH}$ and peak at $2923 \mathrm{~cm}^{-1}$ indicate the presence of $-\mathrm{CH} 2$ radicals, which lead to the spherical structures formation as stated in literature. $[6,42,43]$ The band at 1716 $\mathrm{cm}^{-1}$ attributed to the stretching vibration of $\mathrm{C}=\mathrm{O}$. One of the most characteristic peaks for the CNSs is the $\mathrm{C}=\mathrm{C}$ vibration, which is located all spectra at $1631 \mathrm{~cm}^{-1}$, this band is also reported by others authors[6,43-45] and peak at $749 \mathrm{~cm}^{-1}$ corresponds to the $\mathrm{C}-\mathrm{H}$ aromatic. These results indicate that there are a large number of residues including hydroxyl and carbonyl, carboxyl groups; they provide a 
potential path to load other molecules, functional groups after purification. The as-synthesized CNSs can be used directly to deposit a film $(1.1 \mathrm{~mm})$ on the fourth point of dielectric substrates existing in the conductivity apparatus. These films were conducting in nature with an average sheet resistance of $\mathrm{Rm}=262 \mathrm{k} \Omega / \mathrm{m}$ for approximately $1.1 \mathrm{~mm}$ thickness.

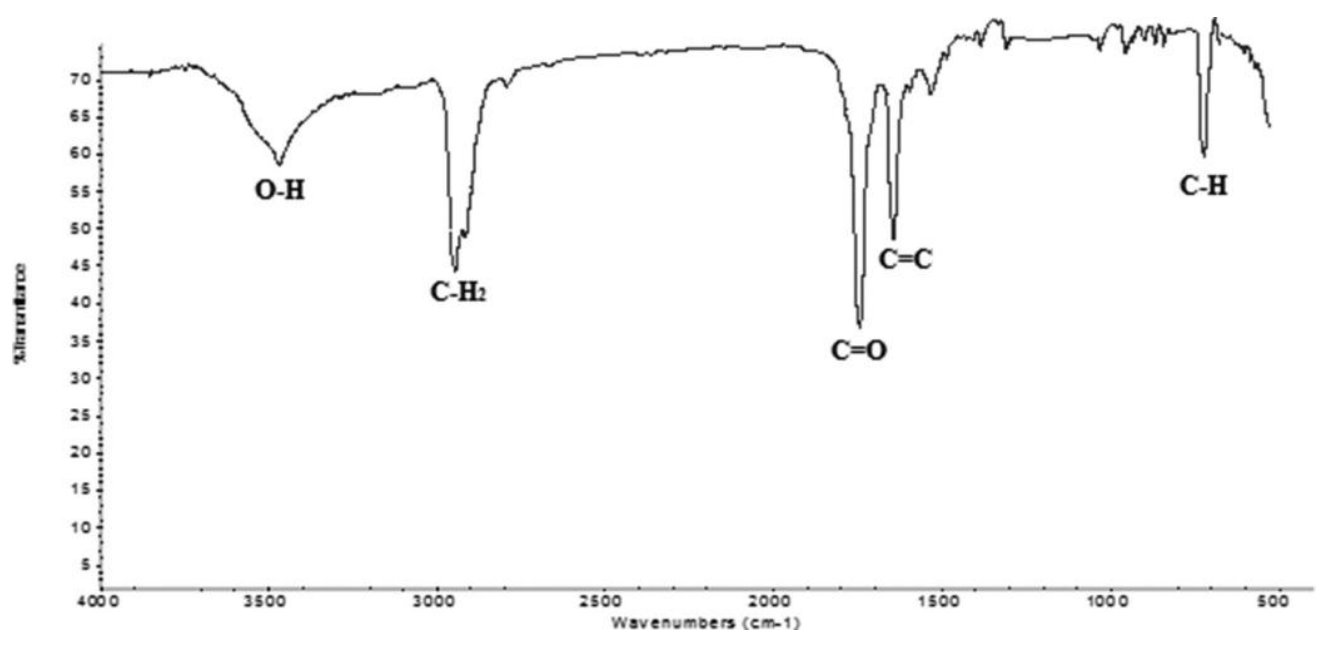

Figure 6. FTIR spectra of carbon spheres obtained via gas condensate pyrolysis.

\section{Conclusion}

In summary, carbon nanospheres were successfully synthesized from gas condensate pyrolysis precursors, with $\mathrm{FeCl}_{3}$ powder as catalyst and nitrogen carrier gas by via CVD method. Here, CNSs with diameter around 100-200 nm was produced with $98 \%$ yield with consuming minimum amount of feed stock $(0.34 \mathrm{~mL} / \mathrm{min} \times 120 \mathrm{~min}=40.8 \mathrm{~mL})$ at $1000^{\circ} \mathrm{C}$ for $2 \mathrm{~h}$; which gives an indication that this process allows for the large scale production of these materials. The product obtained was characterized by the SEM-EDX, TEM, Raman, DRX, and the TGA. The presence of a D-band and a Gband in the Raman spectrum supports the TGA curves which specify the thermal stability of CNSs. The produced CNSs were of non-uniform diameter and the size (nano) could be controlled by changing the pyrolysis experimental conditions. The spheres obtained present major coalescence effects, which could be related to the carbon interactions, promoted by the energy enhancing, but there was no significant effect in their sizes. These results indicate that gas condensate is a promising candidate to be used as precursor in carbon nanomaterials synthesis, which they can be used as potential supercapacitors, lubricants, adsorbents, anode materials for lithium ion batteries, and several new applications.

\section{References}

[1] Inagaki, M. Carbon Materials Structure, Texture and Intercalation. Solid State Ion. 1996, 86-88, 833-839. DOI:10.1016/0167-2738(96)00337-2.

[2] Vishkaei, M. S.; Yunus, R.; Mohd-Salleh, M. A.; Ahmady, A.;Awang-Biak, D. R. Innovative Method to Produce High-Purity Graphitic Carbon Nanospheres. Fuller. Nanotub. Carbon Nanostruct. 2012, 20, 109-118.

DOI: $10.1080 / 1536383 X .2010 .533304$.

[3] Xia, Y.; Gates, B.; Yin, Y.; Lu, Y. Monodispersed Colloidal Spheres: Old Materials with New Applications. Adv. Mater.2000, 12, 693-713.

DOI: 10.1002/(SICI)1521-4095(200005) 12:10<693::AID-ADMA693>3.0.CO;2-J.

[4] Inagaki, M. Discussion of the Formation of Nanometric Texture in Spherical Carbon Bodies. Carbon 1997, 35, 711-714.

DOI: 10.1016/S0008-6223(97)86645-6.

[5] Amit, A.; Deshmukh, A. A.; Mhlanga, S. D.; Coville, N. J. Carbon Spheres. Mater. Sci. Eng. 2010, 70, 1-28.

DOI: 10.1016/j.mser.2010.06.017. 
[6] Gutierrez-Garcia, C. J.; Ambriz-Torres, J. M.; Contreras-Navarrete, J. J.; Granados-Martinez, F. G.; Garcia-Ruiz, D. L.; GarciaGonzalez, L.; Zamora-Peredo, L.; Ortega-Varela, L. F.; Richaud, A.; M_endez, F.; et al. Synthesis of Carbon Spheres by Atmospheric Pressure Chemical Vapor Deposition from a Serial of Aromatic Hydrocarbon Precursors. Physica E: Low-Dimens. Syst. Nanostruct. 2019, 112, 78-85.

DOI: 10.1016/j.physe.2019.04.007.

[7] Washiyama, M.; Sakai, M.; Inagaki, M. Formation of Carbon Spherules by Pressure Carbonization-Relation to Molecular Structure of Precursor. Carbon 1988, 26, 303-307.

DOI: $10.1016 / 0008-6223(88) 90220-5$.

[8] Serp, P. R.; Feurer, R.; Kalck, P.; Kihn, Y.; Faria, J. L.; Figueiredo, J. L. A Chemical Vapour Deposition Process for the Production of Carbon Nanospheres. Carbon 2001, 39, 621-626.

DOI: 10.1016/S0008-6223(00)00324-9.

[9] Thomas, K. M. Hydrogen Adsorption and Storage on Porous Materials. Catal. Today 2007, 120, 389-398.

DOI: 10.1016/j.cattod.2006.09.015.

[10] Alazemi, A. A.; Etacheri, V.; Dysart, A. D.; Stacke, L. E.; Pol, V. G.; Sadeghi, F. Ultrasmooth Submicrometer Carbon Spheres as Lubricant Additives for Friction and Wear Reduction. ACS Appl. Mater. Interfaces 2015, 7, 5514-5521.

DOI: 10.1021/aami.5b00099.

[11] Liu, W.; Qin, L.; An, Z.; Shi, W.; Chen, L.; Liu, X.; Yang, Y. Selective Adsorption and Separation of Dibenzothiophene by Molecularly Imprinted Polymer on the Surface of Porous Magnetic Carbon Nanospheres. Fuller. Nanotub. Carbon. Nanostr 2019, $27,14-22$.

DOI: $10.1080 / 1536383 X .2018 .1476346$.

[12] Ghaemi, F.; Yunus, R.; Mohd-Salleh, M. A.; Lim, H. N.; Suraya Abdul Rashid, S. A. Bulk Production of High-Purity Carbon Nanosphere by Combination of Chemical Vapor Deposition Methods. Fuller. Nanotub. Carbon Nanostruct. $2015,23,1-7$. DOI: 10.1080/1536383X.2014.951439.

[13] Manawi, Y. M.; Ihsanullah, Samara, A.; Al-Ansari, T.; Atieh, M. A. A Review of Carbon Nanomaterials Synthesis via the Chemical Vapor Deposition (CVD) Method. Materials 2018, 11, 822.

DOI: 10.3390/ma11050822.

[14] Koprinarov, N.; Konstantinova, M. Preparation of Carbon Spheres by Low-Temperature Pyrolysis of Cyclic Hydrocarbons. J.

Mater. Sci. 2011, 46, 1494-1501.

DOI: $10.1007 /$ s10853-010-4951-0.

[15] Shao, M.; Ni, Y.; Tong, Y.; Qian, G.; Wei, X. Preparation of Hollow Carbon Nanospheres at Low Temperature via New Reaction Route. J. Solid State Chem. 2005, 178, 908-911.

DOI:10.1016/j.jssc.2004.12.008.

[16] Karna, P.; Ghimire, M.; Mishra, S.; Karna, S. Synthesis and Characterization of Carbon Nanospheres. Open Access Libr. J. 2017, 4, 1-7.

DOI: $10.4236 /$ oalib.1103619.

[17] Hu, G.; Ma, D.; Cheng, M.; Liu, L.; Bao, X. Direct Synthesis of Uniform Hollow Carbon Spheres by a Self-Assembly Template Approach. Chem. Commun. 2002, 17, 1948-1949.

DOI: 10.1039/b205723a.

[18] Vimal, K.; Tiwari; Chen, Z.; Gao, F.; Gu, Z.; Xueliang Sun, X.; Ye, Z. Synthesis of Ultra-Small Carbon Nanospheres (<50 nm) with Uniform Tunable Sizes by a Convenient Catalytic Emulsion Polymerization Strategy: Superior Supercapacitive and Sorption performance. J. Mater. Chem. A 2017, 5, 12131-12143.

DOI: $10.1039 /$ C7TA01114H

[19] Wang, P.; Wei, J.; Huang, B.; Qin, X.; Yao, S.; Zhang, Q.; Wang, Z.; Xu, G.; Jing, X. Synthesis and Characterization of Carbon Spheres Prepared by Chemical Vapour Deposition. Mater. Lett. 2007, 61, 4854-4856.

DOI: 10.1016/j.matlet.2007.03.056.

[20] Hou, H.; Schaper, A. K.; Weller, F.; Greiner, A. Carbon Nanotubes and Spheres Produced by Modified Ferrocene Pyrolysis. Chem. Mater. 2002, 14, 3990-3994.

DOI: $10.1021 / \mathrm{cm} 021206 x$.

[21] Liu, X. Y.; Huang, B. C.; Coville, N. J. The Fe(CO) ${ }_{5}$ Catalyzed Pyrolysis of Pentane: Carbon Nanotube and Carbon Nanoball Formation. Carbon 2002, 40, 2791-2799.

DOI: 10.1016/S0008-6223(02)00193-8.

[22] Govindaraj, A.; Sen, R.; Nagaraju, B. V.; Rao, C. N. R. Carbon Nanospheres and Tubules Obtained by the Pyrolysis of Hydrocarbon. Philos. Mag. Lett. 1997, 76, 363-368.

DOI: $10.1080 / 095008397178977$.

[23] Jin, Y. Z.; Gao, C.; Hsu, W. K.; Zhu, Y.; Huczko, A.; Bystrzejewski, M.; Roe, M.; Lee, C. Y.; Acquah, S.; Kroto, H. et al. Large-Scale Synthesis and Characterization of Carbon Spheres Prepared by Direct Pyrolysis of Hydrocarbons. Carbon 2005, 43, 1944-1953. DOI: 10.1016/j.carbon.2005.03.002.

[24] Zheng, Y.; Zhang, H.; Ge, S.; Song, J.; Wang, J.; Zhang, S. Synthesis of Carbon Nanotube Arrays with High Aspect Ratio via NiCatalyzed Pyrolysis of Waste Polyethylene. Nanomaterials 2018, 8, 556.

DOI: 10.3390/nano8070556.

[25] Castro, A. T.; Luiz, D.; de Castro, L. D. Use of by-Products from Petroleum Production in the Synthesis of Carbon Nanospheres. Polymers 2009, 19, 344-346.

[26] Mohan, A. N.; Manoj, B. Synthesis and Characterization of Carbon Nanospheres from Hydrocarbon Soot. Int. J. Electrochem. Sci. 2012, 7, 9537-9549.

[27] Mohammed, M. I.; Ibrahim, R. I.; Mahmoud, L. H.; Zablouk, M. A.; Manweel, M.; Mahmoud, A. Characteristics of Carbon Nanospheres Prepared from Locally Deoiled Asphalt. Adv. Mater. Sci. Eng. 2013, 2013, 356769.

DOI: 10.1155/2013/356769. 
[28] Mahal, E. S. A.; Sonsudinb, F.; Al-Mutlaqa, S. S.; Yahyaa, R. Core Shell Carbon Nanospheres Synthesis via Semi-Chemical Vapor Deposition Method. Int. J. Sci. Eng. Res. 2014, 5, 392.

[29] Hossain, M. A.; Islam, S.; Chowdhury, F. A.; Mohiuddin, T. G.; Uchida, K.; Tamura, T.; Sugawa, K.; Mochida, T.; Otsuki, J.; Alam, M. S. Structural, Mechanical, and Electrical Properties of Carbon Nanoparticles Synthesised from Diesel. Fuller. Nanotub. Carbon Nanostruct. 2016, 24, 43-51.

DOI: $10.1080 / 1536383 X .2015 .1092436$.

[30] Nandiyanto, M. A.; Fadhlulloh, M. A.; Rahman, T.; Mudzakir, T. Synthesis of Carbon Nanoparticles from Commercially Available Liquified Petroleum Gas. IOP Conf. Ser.: Mater. Sci. Eng. 2016, 128, 012042.

DOI: 10.1088/1757-899X/128/1/012042.

[31] Boufades, D.; Pemanos Yelda, B.; Mousidene, A.; Benmebrouka, H.; Doumandji, L.; Hamada, B. Carbone Nanospheres Synthesis by Pyrolysis of Crude Oil and Optimization of Parameters Growth by Response Surface Methodology (RSM). Elixir Appl. Chem. 2015, 78, 29773-29779.

[32] Frusteri, L.; Cannilla, C.; Barbera, K.; Perathoner, S.; Centi, G.; Frusteri, F. Carbon Growth Evidences as a Result of Benzene Pyrolysis. Carbon 2013, 59, 296-307.

DOI: 10.1016/j.carbon.2013.03.022.

[33] Fan, Y.; Liu, G.; Liu, X.; Xu, B. Study on the Controlled Growth of Carbon Nanospheres from De-Oiled Asphalt. J. Mater. Sci. 2006, 41, 5242-5245.

[34] Pol, V. G.; Motiei, M.; Gedanken, A.; Calderon-Moreno, J. M.; Yoshimura, M. Carbon Spherules: Synthesis, Properties and Mechanistic Elucidation. Carbon 2004, 42, 111-116.

DOI: 10.1016/j.carbon.2003.10.005.

[35] Nieto-Marquez, A.; Romero, R.; Romero, A.; Valverde, J. L. Carbon Nanospheres: Synthesis, Physicochemical Properties and Applications. J. Mater. Chem. 2011, 21, 1664-1672.

DOI: 10.1039/COJM01350A.

[36] Mhlanga, D. S. D.; Coville, N. J.; Iyuke, S. E.; Afolabi, A. S.; Abdulkareem, A. S.; Kunjuzwa, N. Controlled Syntheses of Carbon Spheres in a Swirled floating Catalytic Chemical Vapour Deposition Vertical Reactor. J. Exp. Nanosci. $2010,5,40-51$.

DOI: 10.1080/17458080903242322.

[37] Nieto-M_arquez, A.; Espartero, I.; Lazo, J. C.; Romero, A.; Valverde, J. L. Direct Synthesis of Carbon and Nitrogen-Carbon Nanospheres from Aromatic Hydrocarbons. Chem. Eng. J 2009, 153, 211-216.

DOI: 10.1016/j.cej.2009.06.010.

[38] Wang, W. C.; Yan, L. J.; Shi, F.; Niu, X. L.; Huang, G. L.; Zheng, C. J.; Sun, W. Application of Carbon-Microsphere- Modified Electrodes for Electrochemistry of Hemoglobin and Electrocatalytic Sensing of Trichloroacetic Acid. Sensors 2016, 16, 6. DOI: $10.3390 /$ s16010006.

[39] Kumar, M.; Ando, Y. Single-Wall and Multi-Wall Carbon Nanotubes from Camphor-A Botanical Hydrocarbon. Diam. Relat. Mater. 2003, 12, 1845-1850. DOI: 10.1016/S0925-9635(03)00217-6.

[40] Bajpai, R.; Rapoport, L.; Amsalem, K.; Wagner, H. D. Rapid Growth of Onion-Like Carbon Nanospheres in a Microwave Oven. CrystEngComm 2016, 18, 230-239.

DOI: $10.1039 /$ C5CE01785H.

[41] Fakhru'I-Razi, A.; Danafar, F.; Dayang Radiah, A. B.; Mohd Salleh, M. A. An Innovative Procedure for Large-Scale Synthesis of Carbon Nanotubes by Fluidized Bed Catalytic Vapor Deposition Technique. Fuller. Nanotub. Carbon Nanostruct. 2009, 17, 652-663. 2009,

DOI: $10.1080 / 15363830903291705$.

[42] Jin, Y. Z.; Kim, Y. J.; Gao, C.; Zhu, Y. Q.; Huczko, A.; Endo,M.; Kroto, H. W. High Temperature Annealing Effects on Carbon Spheres and Their Applications as Anode Materials in Li-Ion Secondary Battery. Carbon 2006, 44, $724-729$.

DOI: 10.1016/j.carbon.2005.09.018.

[43] Sun, X.; Li, Y. Colloidal Carbon Spheres and Their Core/Shell Structures with Noble-Metal Nanoparticles. Angew. Chem. Int. Ed. 2004, 43, 597-601.

DOI: 10.1002 /anie.200352386.

[44] Teng, L.; Tang, T. IR Study on Surface Chemical Properties of Catalytic Grown Carbon Nanotubes and Nanofibers. J. Zhejiang Univ. Sci. A 2008, 9, 720-726.

DOI: $10.1631 /$ jzus.A07150.

[45] Tucureanu, V.; Matei, A.; Avram, A. M. FTIR Spectroscopy for Carbon Family Study. Crit. Rev. Anal. Chem. 2016, 46, 502-520. DOI: $10.1080 / 10408347.2016 .1157013$. 